\title{
PREDICTORS OF PSYCHOLOGICAL STRESS OCCURRING AFTER THE FIRST WAVE OF THE COVID-19: A CROSS-SECTIONAL STUDY IN POLAND
}

\section{Piotr Długosz}

Faculty of Social Sciences

Pedagogical University of Krakow, Poland

\section{Abstract:}

The article presents the results of research aimed to identify the predictors of psychological distress among Poles seven months after the occurrence of the first case of COVID-19. In order to gather the research material, the CAWI on-line survey method was applied and carried out within the framework of the Ariadna Research Panel on the sample of 1079 Poles aged 15 and over. The results of the conducted research indicate that Polish society experienced psychological distress as a result of the first wave of the pandemic. According to the Kessler Psychological Distress Scale (K10), no mental disorders were observed among $36 \%$ of Poles, mild mental disorders were observed among $23 \%$ of respondents, average levels of disorders were observed among $18 \%$ of respondents, whereas high levels of disorders were observed among $23 \%$ of respondents. A hierarchical linear regression analysis was used to identify the predictors of psychological distress. In the first stage, socio-demographic variables explained $20 \%$ of the distress variance. In the second stage, the variables measuring social nuisances of the pandemic were introduced, which increased the percentage of the explained stress variance to $33 \%$. In the third stage, the introduced psychological variables increased the percentage of the explained variance to $73 \%$. The main factor which increased stress levels was neuroticism. The conducted analyses have shown that the lack of social, economic and psychological capital significantly increases the susceptibility to distress when a threat to life and health lasts for a prolonged period of time.

Keywords: COVID-19 pandemic, psychological distress, predictors of stress, neuroticism, Poland.

\section{Introduction}

The COVID-19 pandemic has become a global trauma, leading to a deterioration of mental health of millions of people all over the world (Demertzis, Eyerman, 2020; Johnson et. al., 2020). The pandemic has triggered an array of emotional, physical, and economic issues. COVID-19 has already led to diverse mental health problems, including anxiety, depression and post-traumatic stress disorder (Hyland et. al., 2020; Shevlin et. al., 2020; Gerhold 2020; 
Levkovich \& Shinan-Altman 2020; Mazza et. al., 2020). On the basis of a meta-analysis, it has been determined that symptoms of anxiety ( $6.33 \%$ to $50.9 \%$ ), depression ( $14.6 \%$ to $48.3 \%$ ), post-traumatic stress disorder ( $7 \%$ to $53.8 \%$ ), psychological distress $(34.43 \%$ to $38 \%$ ), and stress $(8.1 \%$ to $81.9 \%$ ) have been observed in many countries (Xiong et al., 2020).

The conducted comparative analyses of mental health indices, measured before and during the pandemic, indicate the deterioration of mental health in many countries (Anexity and Depression 2020; Gray et al., 2020; Pierce et al., 2020). Apart from a threat to life and health among the society, nuisances connected with the quarantine, social isolation, deprivation of needs, the loss of job and financial resources, new stressors have emerged during the development of the pandemic. The unpredictability of the nature of the virus creates circumstances of ongoing stress, which can increase the risk of people developing psychological disorders (Zandifar, Badrfam 2020).

The pandemic of COVID-19 is severely affecting mental health worldwide. Considerable knowledge about the influence of the pandemic on mental health has already been acquired (Arora et al., 2020; Salari et al., 2020). Risk factors having influence on the level of experienced psychological distress have been studied to a lesser extent. Numerous research conducted on representative samples indicates that there are individual and group differences in the susceptibility to stress related to the pandemic.

On the basis of the conducted analyses, three groups of predictors having influence on the level of stress experienced during the pandemic have been distinguished. The first category includes socio-demographic variables, such as sex, age, marital status, financial standing, education level and social connections (Li et al., 2020; Flesia et al., 2020; Qiu et al., 2020; Zhou et al., 2020; Duan et al., 2020). The second category of risk factors includes social effects of the pandemic, such as a decrease in social security, the sense of uncertainty, the sense of deprivation and a change in one's lifestyle (Satici et al., 2020; Elis et al., 2020, Shanahan et al., 2020).

The third category of variables includes individual psychological traits, such as neuroticism, stability, optimism and internalisation of control (Flesia et al., 2020; Ferreira et al., 2020; Nikčević et al., 202, Taylor 2019).

The studies into the predictors of stress conducted to date rarely consider the question of influence of factors of social and economic nature. Therefore, in the following stage, an attempt was taken to verify whether secondary effects of the pandemic, such as a change in 
one's lifestyle, deprivation of needs and limitations of social functioning which results from the pandemic will be significant, similarly to demographic or psychological factors.

The main aim of this paper is to demonstrate the predictors of stress and their impact on mental health after the first wave of the pandemic, illustrated by the example of Poland. In the seventh month after the rise of the COVID-19 pandemic, it was possible to estimate social costs of lockdown.

The study of stress and its predictors fits into findings on psychological effects of disasters (Osofsky et al., 2015; Rhodes et al.,2010). Thanks to the acquired knowledge, it will be possible to get to know better the functioning of the society in the situation of a crisis, and develop solutions which could allow for helping people with their return to a good mental wellbeing.

On the basis of the COR stress theory (Hobfoll, 1988, 1989, 1991), a hypothesis that the COVID-19 has lead the Polish society to the loss of psychological and social resources which resulted in psychological distress may be put forward. The higher the sense of the loss of resources among individuals, the higher the level of stress.

\section{Methods}

\subsection{Participants and procedure}

The study was conducted on a representative nationwide Polish sample $(\mathrm{N}=1,079 ; 554$ women; age range $=15$ to $94, \mathrm{M}=42.4, \mathrm{SD}=16.7$ ). The participants were recruited using the Ariadna Polish on-line panel (CAWI). Participants were rewarded for their participation with points collected via their panel membership, the points being exchangeable for rewards in a pool of several hundred products offered by the panel organizers. All participants provided their informed consent.

This method was used due to social isolation, which is taking place during the pandemic. Nonetheless, as shown by the results of research, the questions related to the measurement of mental health indicators conducted with the use of an on-line survey are as accurate as standard paper-and-pencil tests (Brock et al., Coles et al., 2007).

The studies were carried out between the $26^{\text {th }}$ and the $30^{\text {th }}$ of October 2020. On the day of the commencement of the research, there were 1584 cases of COVID-19 in Poland, whereas on the $30^{\text {th }}$ of September there were 1552 cases. The research was conducted a day before the second wave of the pandemic, as from October the number of incidences increased dramatically and by the end of the month there were over 22000 cases. Therefore, the research was conducted in the circumstances of a relative stabilisation of the number of incidences after the 
summer break. It may be assumed that it was a perfect moment to capture the consequences of the pandemic after the first wave.

\subsection{Demographic characteristics}

The research form included questions regarding the following demographic factors: gender, age, education, socio-economic status, marital status and having children, place of residence, religiosity (Table 1 ).

Table 1. Frequency $(\mathrm{N})$ and percentage $(\%)$ of answers to demographic questions.

\begin{tabular}{|c|c|c|c|}
\hline & & $\mathrm{N}$ & $\%$ \\
\hline \multirow[t]{2}{*}{ Gender } & Male & 525 & 49 \\
\hline & Female & 554 & 51 \\
\hline \multirow[t]{5}{*}{ Age } & $15-24$ & 211 & 20 \\
\hline & $25-34$ & 202 & 19 \\
\hline & $35-44$ & 171 & 16 \\
\hline & $45-54$ & 185 & 17 \\
\hline & $>55$ & 310 & 29 \\
\hline \multirow[t]{3}{*}{ Education } & $\begin{array}{l}\text { Below- } \\
\text { secondary }\end{array}$ & 180 & 17 \\
\hline & Secondary & 475 & 44 \\
\hline & Higher & 424 & 39 \\
\hline \multirow{5}{*}{$\begin{array}{l}\text { Monthly } \\
\text { personal } \\
\text { income }\end{array}$} & No income & 91 & 8 \\
\hline & $<3000$ & 437 & 41 \\
\hline & $3001-5000$ & 262 & 24 \\
\hline & $>5001$ & 107 & 10 \\
\hline & Refusal & 183 & 17 \\
\hline \multirow{3}{*}{$\begin{array}{l}\text { Evaluation of } \\
\text { financial } \\
\text { status }\end{array}$} & $\mathrm{Bad}$ & 154 & 14 \\
\hline & Average & 343 & 32 \\
\hline & Good & 582 & 54 \\
\hline \multirow{4}{*}{$\begin{array}{l}\text { Marital } \\
\text { status }\end{array}$} & Single & 305 & 28 \\
\hline & Married & 525 & 49 \\
\hline & Cohabiting & 199 & 18 \\
\hline & Widowed & 50 & 5 \\
\hline \multirow[t]{2}{*}{ Children } & Yes & 374 & 35 \\
\hline & No & 705 & 65 \\
\hline \multirow{5}{*}{$\begin{array}{l}\text { Place of } \\
\text { residence }\end{array}$} & Village & 399 & 37 \\
\hline & $<20000$ & 141 & 13 \\
\hline & $20000-99000$ & 219 & 20 \\
\hline & $\begin{array}{lll}100 & 000-500 \\
000 & & \\
\end{array}$ & 189 & 18 \\
\hline & $>500000$ & 131 & 12 \\
\hline
\end{tabular}




\begin{tabular}{|l|l|c|c|}
\hline Religiosity & Very religious & 98 & 9 \\
\cline { 2 - 4 } & Religious & 592 & 55 \\
\cline { 2 - 4 } & Undecided & 212 & 20 \\
\cline { 2 - 4 } & Non-religious & 177 & 16 \\
\hline
\end{tabular}

\subsubsection{Social capital index}

Social capital is a significant factor which is of a strategic importance in the situation of stress. It provides an individual with the necessary social support (Caplan 1974; Cassel 1976). There is evidence of its positive impact on the psychological well-being of the society (Putnam 2001). In the measurement of social capital, five items were used for asking about the possessed support, with the use of a nominal "yes, no, I don't know" scale. The distribution of the social capital in the researched group is presented below. Scores range from 0 to 5 . The average social capital index was $3.4,(\mathrm{SD}=1,6)$.

Table 2. Frequency (N) and percentage (\%) social capital.

\begin{tabular}{|l|c|c|}
\hline & N & $\%$ \\
\hline Wanted to find a good job & 523 & 49 \\
\hline Found themselves in a difficult situation and needed money & 753 & 70 \\
\hline Got sick and needed care & 829 & 77 \\
\hline Needed to handle official/administrative matters & 797 & 74 \\
\hline Needed help with explaining a complicated case & 772 & 72 \\
\hline
\end{tabular}

\subsection{Measurement of social effects of the pandemic}

\subsubsection{Loss of economic resources index}

The impact of lockdown on the economic status of Poles was researched in-depth as well. To this end, the loss of economic resources index was used. It was made of four yes/no answers to the question if during the pandemic the researched individual experienced the loss of job, a decrease in the number of working hours, taking up remote work, focusing on looking after their children at home. The changes on the labour market were most often based on taking up remote work (15\%), a decrease in one's working hours $(14 \%)$, the loss of job $(6 \%)$ and focusing on looking after children. Scores ranged from 0 to 4 . The higher the score, the bigger the loss of economic resources. The average on the scale was $0.4, \mathrm{SD}=0.5$.

\subsubsection{Life position decrease index}


In order to verify the extent to which the coronavirus epidemic undermined the life position of the respondents, the Cantril Scale (CS) (Levin, Currie 2014) was used to ask about the experienced life position on the scale ranging from 1 to 10 (where 1 is the worst possible life and 10 is the best possible life). The respondents were asked to compare the position they had before the pandemic and the position they have during the quarantine. The average result of the life position before COVID-19 was $6.92, \mathrm{SD}=1.8$, whereas during the quarantine the result was $6.47, \mathrm{SD}=1.9$. The life position decrease index was made on the basis of the calculation of the difference between the position estimated on the day of the research and the position before the pandemic. Scores on this index range from -9 to 9 . Higher results mean a bigger decrease in one's life position. The average on the scale was $0.4, \mathrm{SD}=1.6$. When presented as a percentage, it means that $53 \%$ of respondents have not experienced a decrease in the standard of living, $13 \%$ have experienced its increase, whereas $34 \%$ of respondents have experienced a decrease in the standard of living.

\subsubsection{Life changes index}

The quarantine has forced individuals to change their social practices. After social distancing, lockdown and other restrictions have been imposed, part of Poles had to give up their then-current activities. A change of one's habits may be a serious source of stress, as indicated by research (Holme \& Rache, 1967). The life changes index was constructed on the basis of answers to four questions regarding the fact whether the pandemic had impact on resignation from tourist trips, social and family meetings, participation in cultural events and religious services. The gathered responses indicate that $45 \%$ of respondents resigned from a tourist trip, $39 \%$ resigned from social and family meetings, $56 \%$ of respondents resigned from their participation in cultural events and $32 \%$ of respondents resigned from religious services. Scores ranged from 0 to 4 . The higher the score, the higher the level of life changes. The average on the scale was $1.7, \mathrm{SD}=1.2$.

\subsubsection{Deprivation of needs index}

Apart from a change in social habits, the pandemic has significantly influenced the possibility of satisfying different basic and higher-level needs. The closing-up of shops, shopping malls, fitness centres, workplaces and national borders has resulted in serious restrictions as regards satisfying one's needs. Inability to use social infrastructure and limitations in spending one's free time, entertainment and participation in cultural events may generate frustration and have negative impact on mental health of Poles. 
The deprivation of needs index has been prepared on the basis of answers pertaining to the impact of the COVID-19 pandemic on various aspects of social functioning. The instrument measuring the deprivation of needs includes 8 questions in which respondents marked whether the pandemic had a positive, negative or no impact on a particular aspect of living. Detailed distribution of answers shown in percentage is presented in Table 3.

Table 3. The influence of pandemic on the possibility to fulfil one's needs.

\begin{tabular}{|l|c|c|c|c|c|c|}
\hline \multirow{2}{*}{} & \multicolumn{2}{l|}{\begin{tabular}{l} 
Decreased \\
\multicolumn{2}{|l|}{$\begin{array}{l}\text { Not } \\
\text { changed }\end{array}$}
\end{tabular}} & \multicolumn{2}{l|}{ Increased } \\
\cline { 2 - 8 } & $\mathrm{N}$ & $\%$ & $\mathrm{~N}$ & $\%$ & $\mathrm{~N}$ & $\%$ \\
\hline Possibility to fulfil one's food and nutritional needs & 110 & 10 & 911 & 84 & 58 & 6 \\
\hline Possibility to spend time with their family & 205 & 19 & 718 & 67 & 156 & 14 \\
\hline Fulfilling one's professional duties & 187 & 17 & 834 & 77 & 58 & 5 \\
\hline Financial standing & 283 & 26 & 740 & 69 & 56 & 5 \\
\hline Cultural needs & 430 & 40 & 587 & 54 & 62 & 6 \\
\hline Their own or their children's educational needs & 275 & 27 & 725 & 67 & 59 & 6 \\
\hline Recreational needs & 382 & 35 & 612 & 57 & 85 & 8 \\
\hline Health-related needs & 395 & 37 & 601 & 56 & 83 & 7 \\
\hline
\end{tabular}

The deprivation of needs index consists of answers indicating deterioration of possibilities to satisfy one's needs, and its score ranges from 0 to 8 . The average on the scale was $2.1, \mathrm{SD}=2.1$.

\subsubsection{Mindset changes index}

The pandemic, apart from a decrease in the sense of social security, has lead to the loss of control over one's life and events occurring in it. The table shows distribution of answers, which depict the cognitive effects of COVID-19. The loss of psychological resources index was constructed by means of summing up the answers indicating a decrease in self-confidence in the fields presented in the table. Scores ranged from 0 to 6 . The higher the score, the bigger the loss of psychological resources. The average on the scale was 1.7, $\mathrm{SD}=1.6$.

Table 4. The influence of the pandemic on one's mindset.

\begin{tabular}{|l|l|l|c|}
\hline & Decreased & $\begin{array}{c}\text { Not } \\
\text { changed }\end{array}$ & Increased \\
\hline
\end{tabular}




\begin{tabular}{|l|c|c|c|c|c|c|}
\hline & $\mathrm{N}$ & $\%$ & $\mathrm{~N}$ & $\%$ & $\mathrm{~N}$ & $\%$ \\
\hline The sense of stability and certainty & 403 & 37 & 621 & 58 & 55 & 5 \\
\hline The sense of achieving one's goals & 300 & 28 & 721 & 67 & 58 & 5 \\
\hline The sense of stability in one's workplace & 259 & 24 & 767 & 71 & 53 & 5 \\
\hline The sense of control over events in one's life & 330 & 31 & 673 & 62 & 76 & 7 \\
\hline The sense of being calm and carefree & 435 & 40 & 575 & 53 & 69 & 7 \\
\hline The sense of security in a relationship or marriage & 128 & 12 & 871 & 81 & 80 & 7 \\
\hline
\end{tabular}

\subsubsection{The sense of threat of becoming infected with COVID-19}

The sense of threat of becoming infected with COVID-19 may be a significant factor connected with the creation of stress in the circumstances of the pandemic. By means of an open-ended question, the respondents were asked to estimate the probability of becoming infected with coronavirus on the scale from 0 to 100. Average chances of becoming infected have been estimated to $40.9 \%, \mathrm{SD}=25.8$.

\subsubsection{The level of interest in the information on the pandemic}

Numerous studies indicate that the symptoms of stress intensify together with an increased interest in the pandemic. Therefore, this variable was measured as well. The scale used to measure the level of interest in the pandemic consists of 4 points. The score ranges from 0 to 4 . The responses covered the range from "I'm not interested at all" to "I'm very interested". Higher values indicate a higher interest. The average on the scale was $2.9, \mathrm{SD}=0.7$.

\subsection{Psychological variables}

\subsubsection{The COVID-19 anxiety syndrome scale}

One of the main factors creating stress at the time of the pandemic may be the fear of COVID-19. The virus, which originated in Wuhan is a powerful stressor, and its force of impact was measured with the use of the COVID-19 Anxiety Syndrome Scale (C-19ASS) (Nikčević, Spada 2020). The scale is a new instrument used to measure the COVID-19 anxiety disorder. The version applied in the questionnaire was modified and it consists of nine items. They were constructed with the use of the following expressions: 1) I have avoided using public transport because of the fear of contracting coronavirus (COVID-19), 2) I have checked myself for symptoms of coronavirus (COVID-19), 3) I have avoided going out to public places (shops, parks) because of the fear of contracting coronavirus (COVID-19), 4) I have been concerned 
about not having adhered strictly to social distancing guidelines for coronavirus (COVID-19), 5) I have avoided touching things in public spaces because of the fear of contracting coronavirus (COVID-19), 6) I have read news relating to coronavirus (COVID-19) at the cost of engaging in work (such as writing emails, working on word documents or spreadsheets), 7) I have checked my family members and the loved one for the signs of coronavirus (COVID-19), 8) I have been paying close attention to others displaying possible symptoms of coronavirus (COVID-19), 9) I have imagined what could happen to my family members if they contracted coronavirus (COVID-19).

Respondents were asked to indicate the degree to which they agree with each item on a 5-point Likert-type scale ranging from 1 (definitely not) to 5 (definitely yes). Scores range from 9 to 45 . In the current study, the (C-19ASS) Cronbach $\alpha=0.87$. Higher scores indicate higher levels of anxiety syndrome scale. The average on the COVID-19 anxiety syndrome scale was 26.5, $(\mathrm{SD}=7.7)$.

\subsubsection{The Fear of COVID-19 Scale}

The Fear of COVID-19 Scale (FCV-19S) was developed by Ahorsu et al. The items of the FCV-19S were constructed based on extensive review of existing scales on fears, expert evaluations, and participant interviews (Ahorsu et al. 2020). The FCV-19S consists of 10 items. They were constructed with the use of the following expressions: 1) I am most afraid of COVID-19, 2) It makes me uncomfortable to think about COVID-19, 3) My hands become clammy when I think about COVID-19, 4) I am afraid of losing my life because of COVID-19, 5) While watching news and stories about COVID-19 on social media, I become nervous or anxious, 6) I cannot sleep because I'm worrying about getting COVID-19, 7) My heart races or palpitates when I think about getting COVID-19, 8) COVID-19 is almost always lethal, 9) COVID-19 is an unpredictable disease, 10) I am very worried about COVID-19.

The response for each item was recorded according to a 5-point Likert scale ranging from 1 (definitely not) to 5 (definitely yes). The overall score of fear (ranging from 10 to 50) was obtained by adding up each item score. The higher the overall score, the greater the fear of COVID-19. Cronbach $\alpha=0.93$. The average fear on COVID-19 Scale was 23,7, SD=9.

\subsubsection{Neuroticism}

Neuroticism is deemed a crucial stress factor (Eysenck 1990). Neuroticism is a personality trait, which is characterised by a tendency to the occurrence of negative emotions, 
such as depression, anxiety or anger. Individuals with high neuroticism scores perceive the world as threatening, they are quickly distressed, and it is difficult for them to cope with stressful situations (Cohen et al., 2012). The studies into fear of COVID-19 have shown that neuroticism as one of elements of the Big Five has a negative impact on mental health during the COVID-19 pandemic (Nikčević et al., 2020).

The scale used to measure neuroticism was constructed according to the model of the Neuroticism Scale of the Eysenck Personality Questionnaire-Revised (EPQ-R) (Eysenck \& Eysenck, 1975). It consists of 13 items. The response for each item was recorded according to a 5-point Likert scale ranging from 1 (definitely not) to 5 (definitely yes). Scores on this scale ranged from 13 to 65 , with higher scores indicating higher levels of neuroticism. Coefficient alpha in the present study was 0.87 . The average (EPQ-R) was 38.0, SD=8.

\section{Results}

\subsection{Psychological Distress}

In order to measure the dependent variable, the Kessler Psychological Distress Scale (K10) which measures the symptoms of anxiety and depression in the society was used (Kessler et al., 2003). The scale consists of 10 items and its Cronbach $\alpha=0.948$. The response for each item was recorded according to a 5-point Likert scale ranging from 1 (All of the time) to 5 (None of the time).

The minimum value on the scale was 10 , whereas the maximum value was 50 . The average value for the researched sample was $\mathrm{M}=22.9, \mathrm{SD}=8.1$. According to the scale's diagnostic criteria (Kessler et al., 2003), the lack of mental disorders (up to 10 points) was observed among $36 \%$ of respondents. Mild disorders (20-24 points) were observed among $23 \%$ of respondents. An average level of disorders (25-30 points) was observed among $18 \%$ of respondents. High levels of disorders (more than 30 points) was observed among $23 \%$ of Poles.

Table 5. The distribution of answers on the distress scale.

\begin{tabular}{|l|l|}
\hline & Mean (95\% CI $)^{1}$ \\
\hline $\begin{array}{l}\text { In the past } 4 \text { weeks, about how often did you feel tired out for no } \\
\text { good reason? }\end{array}$ & $2.57(2.51-2.63)$ \\
\hline In the past 4 weeks, about how often did you feel nervous? & $2.61(2.55-2.66)$ \\
\hline $\begin{array}{l}\text { In the past } 4 \text { weeks, about how often did you feel so nervous that } \\
\text { nothing could calm you down? }\end{array}$ & $2.04(1.98-2.09)$ \\
\hline In the past 4 weeks, about how often did you feel hopeless? & $2.33(2.27-2.39)$ \\
\hline In the past 4 weeks, about how often did you feel restless or fidgety? & $2.55(2.49-2.60)$ \\
\hline
\end{tabular}

\footnotetext{
${ }^{1} \mathrm{Cl}$, confidence interval.
} 


\begin{tabular}{|l|l|}
\hline $\begin{array}{l}\text { In the past } 4 \text { weeks, about how often did you feel so restless you } \\
\text { could not sit still? }\end{array}$ & $2.02(1.97-2.08)$ \\
\hline In the past 4 weeks, about how often did you feel depressed? & $2.45(2.39-2.51)$ \\
\hline $\begin{array}{l}\text { In the past } 4 \text { weeks, about how often did you feel that everything was } \\
\text { an effort? }\end{array}$ & $2.21(2.15-2.27)$ \\
\hline $\begin{array}{l}\text { In the past } 4 \text { weeks, about how often did you feel so sad that nothing } \\
\text { could cheer you up? }\end{array}$ & $2.11(2.05-2.17)$ \\
\hline In the past 4 weeks, about how often did you feel worthless? & $2.10(2.03-2.16)$ \\
\hline
\end{tabular}

The correlation between the scale of stress and the predictors taken into account in the analysis are presented in Table 6. The results of the correlation analysis indicate that all the three groups of variables are statistically relevant. The variables, such as neuroticism, the fear of COVID-19, the sense of threat of COVID-19 and evaluation of one's financial situation are correlated with stress to the most significant extent. This confirms the hypothesis indicating the increase of the pandemic-related stress as a result of the loss of resources. The loss of financial resources, a decrease in social security and a decrease in the sense of psychological security have impact on the creation of stress. The higher the loss of resources, the stronger the psychological discomfort. 


\begin{tabular}{|c|c|c|c|c|c|c|c|c|c|c|c|c|c|c|c|c|c|c|c|c|}
\hline Variables & 2 & 3 & 4 & 5 & 6 & 7 & 8 & 9 & 10 & 11 & 12 & 13 & 14 & 15 & 16 & 17 & 18 & 19 & 20 & 21 \\
\hline 1.Gender & -.03 & -.00 & .03 & .05 & .04 & $.10^{* * *}$ & $-.09 * *$ & .02 & .04 & -.02 & .05 & $-.11 * *$ & .01 & -.01 & $-.12 * *$ & $-.12 * *$ & $-.12 * *$ & .02 & -.03 & -.05 \\
\hline 2.Age & & .20 ** & $.30^{* * *}$ & .05 & .00 & $.08 * *$ & $.22 * *$ & $-.12 * *$ & .02 & $.20 * *$ & .03 & $.09 * *$ & $.12 * *$ & $-.12 * *$ & $.20 * *$ & $.15^{* * *}$ & -.28 & $.11 * *$ & $.14 * *$ & $-.23 * *$ \\
\hline 3. Place of residence & & & $.13 * *$ & $.13 * *$ & .02 & .04 & $.07 * *$ & $-.06 * *$ & $.08^{* *}$ & $.08 * *$ & -.00 & $.07 * *$ & $.07 * *$ & .01 & $.10 * *$ & $.06^{* * *}$ & $-.08 * *$ & .02 & .02 & -.04 \\
\hline 4.Education & & & & $.40 * *$ & $.11 * *$ & $.23 * *$ & .01 & -.02 & -.02 & $.11 * *$ & .04 & $.13^{* *}$ & .02 & $.17 * *$ & $.15^{* *}$ & $.20 * *$ & $-.13 * *$ & $.06 * *$ & -.03 & $-.11 * *$ \\
\hline 5.Father's education & & & & & $.08 * *$ & $.12 * *$ & $-.07 *$ & .00 & .02 & .01 & .02 & .00 & -.02 & $.06^{*}$ & .02 & $.09 * *$ & -.02 & .00 & -.04 & -.01 \\
\hline $\begin{array}{l}\text { 6. Evaluation of } \\
\text { financial status }\end{array}$ & & & & & & $.16^{* * *}$ & -.08 & $.18^{* * *}$ & $-.06^{*}$ & .02 & .04 & $-.19 * *$ & $-.22 * *$ & $-.08^{* *}$ & $-.17 * *$ & .03 & $-.27 * *$ & $-.07 *$ & $-.17 * *$ & $-.29^{* *}$ \\
\hline $\begin{array}{l}\text { 7.Monthly personal } \\
\text { income }\end{array}$ & & & & & & & -.00 & -.01 & -.01 & -.02 & .05 & $-.08^{* *}$ & -.04 & .01 & $-.06^{*}$ & .04 & $-.12 * *$ & -.00 & -.03 & -.10 \\
\hline 8.Marital status & & & & & & & &,- 02 & .00 & $.06^{*}$ & .05 & $.06^{*}$ & $.06 *$ & .03 & $.09 * *$ & .05 & $-.06 *$ & $.09^{* *}$ & $.09 * *$ & -.01 \\
\hline $\begin{array}{l}\text { 9. Social capital } \\
\text { index }\end{array}$ & & & & & & & & & $-.08 * *$ & .00 & -.03 & $-.16^{* *}$ & $-.11 * *$ & -.01 & $-.09 * *$ & -.00 & $-.11 * *$ & .01 & $-.06^{*}$ & $-.12 * *$ \\
\hline 10. Religiosity & & & & & & & & & & $-.07 *$ & -.01 & $.08 * *$ & .01 & -.00 & $.09 * *$ & -.01 & $-.09 * *$ & -.04 & $-.06 *$ & .01 \\
\hline $\begin{array}{l}\text { 11. The level of } \\
\text { interest in the } \\
\text { information on the } \\
\text { COVID-19 } \\
\text { pandemic }\end{array}$ & & & & & & & & & & & $.28 * *$ & $.17^{* * *}$ & $.08 * *$ & $09 * *$ & $.13 * *$ & $.26 * *$ & $.07 *$ & $.53 * *$ & $.42 * *$ & $.12 * *$ \\
\hline $\begin{array}{l}\text { 12. The sense of } \\
\text { threat of becoming } \\
\text { infected with } \\
\text { COVID-19 }\end{array}$ & & & & & & & & & & & & $.13^{* *}$ & .03 & $.15^{* *}$ & $.12 * *$ & $.19 * *$ & $.19 * *$ & $.43 * *$ & $.43 * *$ & $.29 * *$ \\
\hline $\begin{array}{l}\text { 13. Mindset change } \\
\text { index }\end{array}$ & & & & & & & & & & & & & $.29 * *$ & $.19^{* *}$ & $.55^{* * *}$ & $.29 * *$ & $.18 * *$ & $.16^{* * *}$ & $.13^{* * *}$ & $.16 * *$ \\
\hline $\begin{array}{l}\text { 14. Life position } \\
\text { decrease index }\end{array}$ & & & & & & & & & & & & & & .09 ** & $.27 * *$ & $.18^{* * *}$ & $.08^{* *}$ & $.12 * *$ & $.15^{* * *}$ & $.12 * *$ \\
\hline $\begin{array}{l}\text { 15. Loss of } \\
\text { economic resources } \\
\text { index }\end{array}$ & & & & & & & & & & & & & & & $.20 * *$ & $.18^{* * *}$ & $.09 * *$ & $.16^{* * *}$ & $.09 * *$ & $.14 * *$ \\
\hline $\begin{array}{l}\text { 16. Deprivation of } \\
\text { needs index }\end{array}$ & & & & & & & & & & & & & & & & .31 ** & .02 & $.11 * *$ & $.08^{* *}$ & .05 \\
\hline $\begin{array}{l}\text { 17. Life changes } \\
\text { index }\end{array}$ & & & & & & & & & & & & & & & & & .05 & $.38 * *$ & $.25 * *$ & $.09 * *$ \\
\hline 18.Neuroticism & & & & & & & & & & & & & & & & & & $.20 * *$ & $.35 * *$ & $.76^{* * *}$ \\
\hline 19.C-19ASS & & & & & & & & & & & & & & & & & & & $.70 * *$ & $.28 * *$ \\
\hline 20.FCV-19S & & & & & & & & & & & & & & & & & & & & $.48 * *$ \\
\hline $\begin{array}{l}\text { 21.Psychological } \\
\text { Distress K10 }\end{array}$ & & & & & & & & & & & & & & & & & & & & \\
\hline
\end{tabular}

${ }^{*} \mathrm{p} \leq .05 ; * * \mathrm{p} \leq .01$ 


\author{
doi:10.20944/preprints202103.0768.v1 更

$\sqrt{2}$

(1)
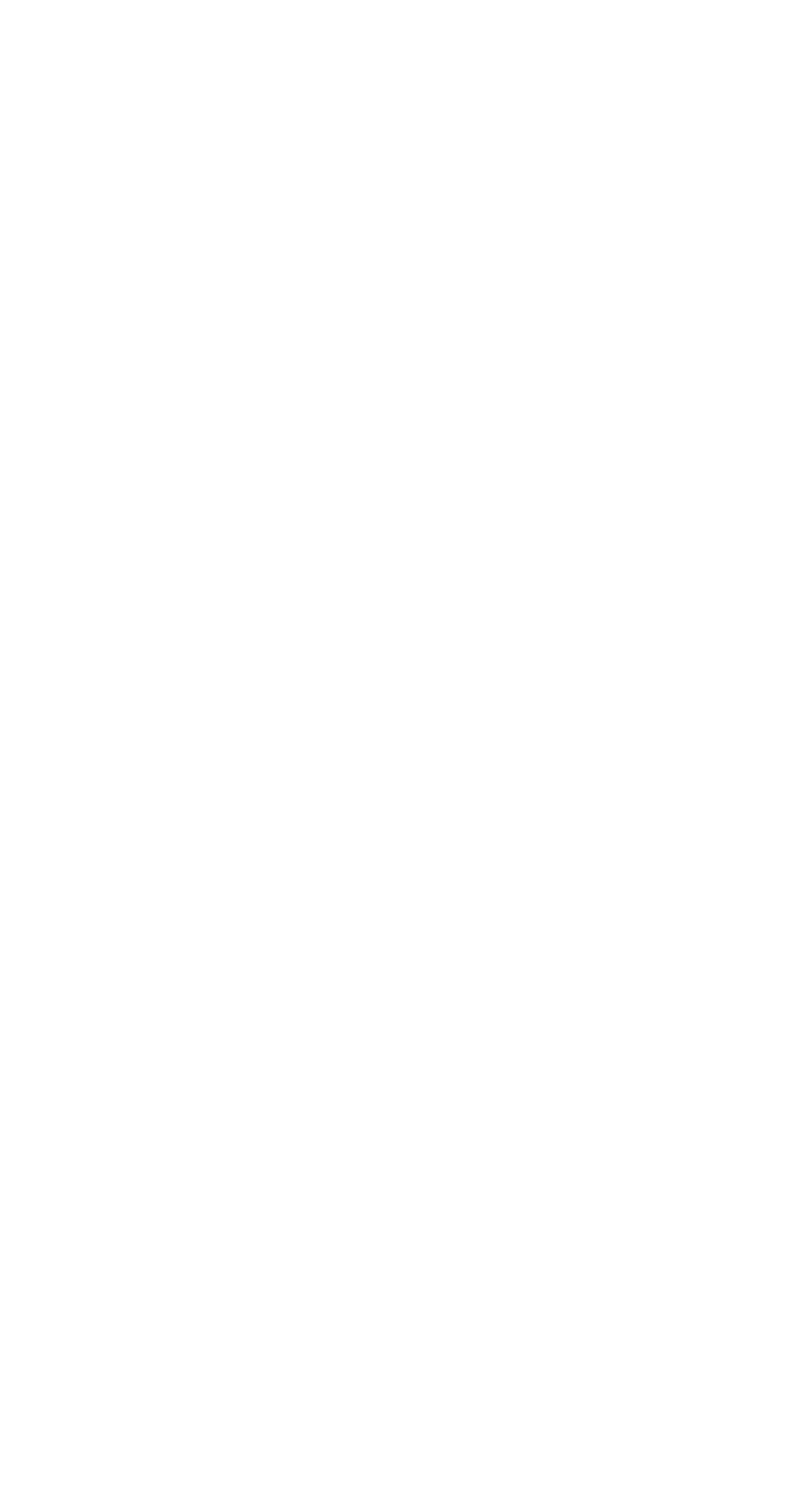
Hierarchical regression analysis was used to study the relationship between sociodemographic, psychological, social effect variables and the level of stress. In the first stage, socio-demographic variables were introduced, in the second stage, the variables measuring negative effects of lockdown and the level of interest in the information on the pandemic were applied, and in the third stage, the psychological variables were introduced to the model.

The results of the hierarchical regression analysis indicate the fact that demographic variables explain $20 \%$ of stress variance. Higher levels of stress were experienced by females, young people, lonely people, people whose father's education was lower, people deprived of social support and assessing their financial standing as worse.

Introducing variables measuring social effects of lockdown to the model resulted in a significant change in corrected R2, (delta corrected R2 $=.113$; F change $(10,1068)=19.508, p$ $<.000$ ), and indicates that introducing those variables has increased the level of explained variance to $33 \%$. The sense of threat of becoming infected with COVID-19 and the loss of economic resources index turned out to be statistically relevant. The variables from the first model (age, father's education, marital status and social capital) have retained their impact. Gender and evaluation of financial status turned out to be statistically irrelevant. In the third stage, upon introducing psychological variables, the level of explained variance was $73 \%$. The change in the explained variance was statistically relevant. A significant change in corrected $\mathrm{R} 2$, (delta corrected R2 $=.386$; F change $(3,1058)=393.613, \mathrm{p}<.000)$ was observed. In this model, neuroticism was the strongest stress predictor. The C-19ASS and the FCV-19S scales had a lesser impact on stress levels. Age, evaluation of financial status and religiosity from the first model remained statistically relevant. The level of interest in the information on the pandemic from the first model was introduced in the calculation.

Table 7. Results of multiple regression analyses predicting the level of psychological distress.

\begin{tabular}{|l|c|c|c|c|c|c|}
\hline & \multicolumn{2}{|l|}{ Model I } & \multicolumn{2}{l|}{ Model II } & \multicolumn{2}{l|}{ Model III } \\
\hline Variables & $\beta$ & $\mathrm{p}$ & $\beta$ & $\mathrm{p}$ & $\beta$ & $\mathrm{p}$ \\
\hline Gender & 0.176 & 0.054 & 0.117 & 0.177 & 0.082 & 0.135 \\
\hline Age & -0.237 & 0.011 & -0.169 & 0.054 & -0.113 & 0.052 \\
\hline Place of residence & 0.080 & 0.360 & 0.066 & 0.430 & 0.094 & 0.080 \\
\hline Education & 0.043 & 0.625 & 0.066 & 0.431 & -0.026 & 0.620 \\
\hline Father's education & 0.186 & 0.037 & 0.133 & 0.013 & 0.041 & 0.436 \\
\hline Evaluation of financial & -0.236 & 0.047 & -0.222 & 0.066 & -0.154 & 0.036 \\
status & & & & & & \\
\hline Monthly personal income & -0.031 & 0.734 & -0.041 & 0.665 & 0.033 & 0.556 \\
\hline Marital status & 0.211 & 0.026 & 0.185 & 0.049 & 0.069 & 0.249 \\
\hline
\end{tabular}




\begin{tabular}{|c|c|c|c|c|c|c|}
\hline Social capital index & -0.196 & 0.047 & -0.209 & 0.028 & -0.080 & 0.182 \\
\hline Religiosity & -0.035 & 0.705 & 0.061 & 0.535 & 0.180 & 0.002 \\
\hline $\begin{array}{l}\text { The level of interest in the } \\
\text { information on the } \\
\text { COVID-19 pandemic }\end{array}$ & - & - & 0.125 & 0.187 & 0.130 & 0.046 \\
\hline $\begin{array}{l}\text { The sense of threat of } \\
\text { becoming infected with } \\
\text { COVID-19 }\end{array}$ & - & - & 0.335 & 0.000 & 0.082 & 0.196 \\
\hline $\begin{array}{l}\text { Loss of psychological } \\
\text { resources index }\end{array}$ & - & - & 0.081 & 0.480 & -0.033 & 0.971 \\
\hline $\begin{array}{l}\text { Life position decrease } \\
\text { index }\end{array}$ & - & - & -0.064 & 0.718 & 0.005 & 0.936 \\
\hline $\begin{array}{l}\text { Loss of economic } \\
\text { resources index }\end{array}$ & - & - & 0.164 & 0.055 & 0.074 & 0.190 \\
\hline $\begin{array}{l}\text { Deprivation of needs } \\
\text { index }\end{array}$ & - & - & -0.159 & 0.155 & 0.058 & 0.421 \\
\hline Life changes index & - & - & -0.059 & 0.536 & -0.084 & 0.180 \\
\hline Neuroticism & - & - & - & - & 0.640 & 0.000 \\
\hline C-19ASS & - & - & - & - & -0.179 & 0.028 \\
\hline FCV-19S & - & - & - & - & 0.256 & 0.002 \\
\hline $\mathrm{F}(\mathrm{p} \leq 0.000)$ & \multicolumn{2}{|c|}{2.813} & \multicolumn{2}{|c|}{3.520} & \multicolumn{2}{|c|}{13.892} \\
\hline $\mathrm{R}$ square & \multicolumn{2}{|c|}{0.195} & \multicolumn{2}{|c|}{0.332} & \multicolumn{2}{|c|}{0.738} \\
\hline Standard error & \multicolumn{2}{|c|}{6.575} & \multicolumn{2}{|c|}{5.992} & \multicolumn{2}{|c|}{3.754} \\
\hline
\end{tabular}




\section{Discussion}

The aim of this paper is to determine risk factors increasing the levels of experienced stress after the first wave of the pandemic. It has been assumed that the level of stress will be determined by the loss of financial, social and psychological resources (Hobfoll 1991).

The results of linear regression analysis partially confirm the assumed hypothesis. By means of analyses, it has been shown that three factors determine the level of stress. Sociodemographic variables explain only $20 \%$ of the dependent variable variance. Higher levels of stress were observed among females, young people, single people, people whose father's education was lower and people who were devoid of social capital and evaluated their financial standing as worse.

The predictors distinguished in the first regression model indicate that the highest level of distress could be observed among the youngest age groups. These results are consistent with the findings of researchers from many different countries (Branquinho et. al., 2020; Gray et. al., 2020). Meta-analyses also indicate a worse mental condition of young people in the time of the COVID-19 pandemic (de Miranda, et. al., 2020). Higher levels of stress may be explained by the fact that, first of all, just before the pandemic youth had a worse mental condition than adults (Putnam 2000; Twenge 2017). The pandemic might have intensified these trends. Secondly, among younger age groups, peer relations are the main need (Smetana et. al., 2006). Quarantine and social distancing have resulted in a deprivation of this need, at the same time deepening the distress (Brooks et al., 2020). The analyses have analogically shown higher levels of stress among females, similarly to other studies (Luo et al., 2020). The influence of gender may be explained by the fact that emotional stability is lower in women and increases in later years (Marsh et al., 2012). A higher distress was observed among people with lower social capital and lonely people, which may indicate the crucial role of social support in the time of the threat of the pandemic. Married people and people who have others willing to help cope with the pandemic better, which is indicated by many other studies (Luo et al., 2020). Respondents in a worse financial situation had a worse mental health. This may mean that the lack of financial resources lowers adaptive capabilities. Together with the decrease of the respondent's father's education, distress increases, which may confirm the impact of cultural resources on mental health. The respondent's father's education may be a better index of cultural capital due to the fact that higher education has become popularised and suffers inflation (Wilson 1999; Colins 2019). This may mean that higher social standing prevents individuals from experiencing stress. 
In the second model of regression analysis, the indices aimed at indicating secondary effects of the pandemic, such as limitations of social activities or limitations in satisfying one's needs were introduced. It has been shown that the level of explained variance of the distress scale has increased by more than $10 \%$. Variables, such as father's education, marital status and social capital turned out to be statistically relevant. Moreover, it was observed that people indicating a higher probability of becoming infected with coronavirus and experiencing financial losses due to the pandemic had higher levels of stress. This may confirm the theory of the impact of the loss of resources on experienced stress (Hobfoll 1989). A prospective loss of health resources and the actual loss of financial resources increase the results on the stress scale.

In the third model, psychological variables were introduced to the analysis, thanks to which the level of explained variance on the stress scale has increased to $40 \%$. Furthermore, significant predictors of the experienced stress have changed as well. Age has retained its impact on the level of stress. The importance of the evaluation of financial status has retained its importance. Religiosity and the level of interest in the information pertaining to coronavirus has been included in the explanation of the dependent variable. Higher levels of stress were observed among people undecided in terms of faith and those who are more interested in the information about the pandemic. This may mean that the media have a negative impact on mental health of individuals, which is confirmed by other studies as well (Liu et al., 2020; Malesza, Kaczmarek 2020). Nonetheless, the results on the scale of fear of COVID-19, the COVID-19 anxiety syndrome scale and the neuroticism scale had the strongest impact on the observed stress levels. The two first variables may be perceived as stressors. The higher the level of anxiety and fear of COVID-19, the higher the levels of stress. This relationship has been observed in other studies as well. Nevertheless, among all of the variables, neuroticism had the strongest force of impact. This may mean that neuroticism is a moderator of stress and acts as an intermediary in the perception of reality. In the situation of threat of the pandemic, it increases the sense of threat and by the same means it significantly increases the level of psychological distress, which is indicated by other studies (Kroencke et al., 2020; Caci et. al., 2020; Nikčević et. al., 2020).

\section{Conclusions}

The results of research conducted after the first wave of the COVID-19 pandemic (seven months after the occurrence of COVID-19 in Poland) indicate that only 36\% of Poles have not experienced psychological distress. The respondents experienced anxiety, irritability, fatigue 
and gloom most often. The pandemic and threat posed by it which last for a long time have led to a bad mental condition.

The main factor which had impact on psychological distress was neuroticism. Emotionally unstable individuals, people with higher levels of fear and depression had a difficulty coping with the threat and the situation of uncertainty in the time of the pandemic. Apart from neuroticism, socio-demographic variables and experienced financial losses had impact on distress. The results of research indicate that psychological, social and financial resources may protect individuals from the COVID-19-related distress. Therefore, during and after the pandemic, the main focus should be providing people who are lonely, lost their jobs and income due to the pandemic and those who present neurotic disorders with support and care.

\section{Limitations}

The presented research has certain limitations. First of all, research was conducted during a relative decrease in the number of COVID-19 incidences, after the summer break, during which the society could have forgotten about the threat, which as a result could influence the obtained results. Secondly, the on-line survey (CAWI) has an over-representation of respondents with education higher than Poles in general, in spite of all the attempts to provide a representative sample. Elderly and poor people as well as those with no Internet connection could have been passed over in the research sample. Thirdly, the study was of a cross-cutting nature. Therefore, it is difficult to evaluate to what extent the COVID-19 influenced the mental health of Polish sociey.

\section{References}

Ahorsu, D. K., Lin, C. Y., Imani, V., Saffari, M., Griffiths, M. D., \& Pakpour, A. H. (2020). The Fear of COVID-19 Scale: Development and Initial Validation. International Journal of Mental Health and Addiction, 1-9. Advance online publication. https://doi.org/10.1007/s11469-020-00270-8.

Rhodes, J., Chan, C., Paxson, C., Rouse, C. E., Waters, M., \& Fussell, E. (2010). The impact of hurricane Katrina on the mental and physical health of low-income parents in New Orleans. American Journal of Orthopsychiatry, 80, 237-247. http://dx.doi.org/10.1111/j.1939-0025 $.2010 .01027 . x$.

Anxiety and Depression (2020). National Center for Health Statistics, https://www.cdc.gov/nchs/covid19/pulse/mental-health.htm.

Marsh, H. W., Nagengast, B., \& Morin, A. J. S. (2013). Measurement Invariance of Big-Five Factors Over the Life Span: ESEM Tests of Gender, Age, Plasticity, Maturity, and LaDolce Vita Effects. Developmental Psychology. 49,1194-1218. doi: 


\subsection{7/a0026913.}

Branquinho, C, Kelly, C, Arevalo, L.C, Santos, A, Gaspar de Matos, M.(2020). "Hey, we also have something to say": a qualitative study of Portuguese adolescents' and young people's experiences under COVID-19. Journal of Community Psychology;1-13. https://doi.org/10.1002/jcop.22453.

Brock. R.L, Barry. R.A, Lawrence. E, Dey. J, Rolffs. J. (2012). Internet Administration of Paper-and-Pencil Questionnaires Used in Couple Research. Assessing Psychometric Equivalence. Assessment, 19(2):226-242. doi:10.1177/1073191110382850.

Brooks, S. K., Webster, R. K., Smith, L. E., Woodland, L., Wessely, S., Greenberg, N., \& Rubin, G. J. (2020). The psychological impact of quarantine and how to reduce it: rapid review of the evidence. The Lancet, 395, 912-920. https://doi.org/10.1016/S0140-6736(20)30460-8.

Caci, B, Miceli, S, Scrima, F, and Cardaci, M. (2020.) Neuroticism and Fear of COVID-19. The Interplay Between Boredom, Fantasy Engagement, and Perceived Control Over Time.

Frontiers in Psychology. 11:574393. doi: 10.3389/fpsyg.2020.574393.

Caplan, G. (1974). Support systems and community mental health: Lectures on concept development. Pasadena, CA, US: Behavioral Publications.

Cassel, J. (1976). The contribution of the social environment to host resistance. American Journal of Epidemiology, 104(2), 107-123.

Cohen, S, Janicki-Deverts, D, Crittenden, C.N, Sneed, R.S. (2012). Personality and Human Immunity. In: Segerstrom SC, editor. The Oxford Handbook of Psychoneuroimmunology. Oxford: Oxford University Press; pp. 146-169.

Coles, M.E., Cook, L.M., Blake, T.R. (2007). Assessing obsessive compulsive symptoms and cognitions on the internet: Evidence for the comparability of paper and internet administration. Behaviour Research and Therapy,45(9):2232-2240.

Collins, R. (2019). The credential society: An historical sociology of education and stratification. Columbia University Press.

de Miranda, D. M., da Silva Athanasio, B., de Sena Oliveira, A. C., \& Silva, A. C. S. (2020). How is COVID-19 pandemic impacting mental health of children and adolescents? International Journal of Disaster Risk Reduction. 101845. doi.org/10.1016/j.ijdrr.2020.101845.

Demertzis, N., Eyerman R. (2020). Covid-19 as cultural trauma. American Journal of Cultural Sociology.8,428-450 (2020). https://doi.org/10.1057/s41290-020-00112-z

Eysenck, H. J. (1990). Biological dimensions of personality. In: Pervin LA (eds.). Handbook of personality: theory and research. Guilford Press, New York 1990: 244-276.

Eysenck, H.J., \& Eysenck, S.B. (1975). Eysenck personality questionnaire manual. San Diego,CA: Educational and Industrial Testing Service. 
Gerhold, L. (2020). COVID-19: Risk perception and Coping strategies. Results from a survey in Germany. PsyArXiv, 25 Mar. doi: 10.31234/osf.io/xmpk4.

Gray, N.S, O'Connor, C, Knowles, J, Pink, J, Simkiss, N.J, Williams, S.D and Snowden, R.J. (2020). The Influence of the COVID-19 Pandemic on Mental Well-Being and Psychological Distress: Impact Upon a Single Country. Frontiers in Psychiatry, 11:594115. doi: 10.3389/fpsyt.2020.594115.

Hobfoll, S. E. (1988). The ecology of stress. Washington DC: Hemisphere Publishing.

Hobfoll, S. E. (1989). Conservation of resources: A new attempt at conceptualizing stress. American Psychologist, 44 (3), 513-524.

Hobfoll, S. E. (1991). Traumatic stress: A theory based on rapid loss od resources. Anxiety Research, 4, 187-197.

Holmes, T. H., \& Rahe, R. H. (1967). The Social Readjustment Rating Scale. Journal of Psychosomatic Research, 11(2), 213-218. https://doi.org/10.1016/0022-3999(67)90010-4.

Hyland, P., Shevlin, M., McBride, O., Murphy, J., Karatzias, T., Bentall, R.P., Martinez, A., Vallières, F. (2020). Anxiety, depression, and traumatic stress in the UK general population during the COVID-19 pandemic. www.https://psyarxiv.com. [on 28. December 2020].

Johnson, M. T., Johnson, E. A., Webber, L., \& Nettle, D. (2020). Mitigating social and economic sources of trauma: The need for universal basic income during the coronavirus pandemic. Psychological Trauma: Theory, Research, Practice, and Policy, 12(S1), S191-S192. http://dx.doi.org/10.1037/tra0000739.

Kessler, R, Barker, P, Colpe, L,Epstein, J. Gfroerer, J, Hiripi, E. (2003). Screening for serious mental illness in the general population. Arch Gen Psychiatry, 60(2):184-9. doi: 10.1001/archpsyc.60.2.184. PMID: 12578436.

Kroencke, L., Geukes, K., Utesch, T., Kuper, N., \& Back, M. D. (2020). Neuroticism and emotional risk during the COVID-19 pandemic. Journal of Research in Personality, 89, 104038. https://doi.org/10.1016/j.jrp.2020.104038.

Levin, K.A, Currie, C. (2013). Reliability and validity of adapted version of the Cantril Ladder for use with adolescent sample. Social Indicators Research,119:1047-63.

Levkovich, I., \&Shinan-Altman, S. (2020). Impact of the COVID-19 pandemic on stress and emotional reactions in Israel: A mixed-methods study. 27 May 2020, PREPRINT (Version 1) available at Research Square [+https://doi.org/10.21203/rs.3.rs-30346/v1+].

Luo, M., Guo, L., Yu, M., Jiang, W., \& Wang, H., (2020). The psychological and mental impact of coronavirus disease 2019 (COVID-19) on medical staff and general public - A systematic review and meta-analysis. Psychiatry Research, 291, 113190 https://doi.org/10.1016/j.psychres.2020.113190.

Malesza, M., \& Kaczmarek, M. C. (2020). Predictors of anxiety during the COVID-19 pandemic in Poland. Personality and Individual Differences, 170, 110419. 
Marsh, H. W., Nagengast, B., \& Morin, A. J. S. (2013). Measurement Invariance of Big-Five Factors Over the Life Span: ESEM Tests of Gender, Age, Plasticity, Maturity, and LaDolce Vita Effects. Developmental Psychology. 49,1194-1218. doi: 10.1037/a0026913.

Mazza, C., Ricci, E., Biondi, S., Colasanti, M., Ferracuti, S., Napoli, C., \& Roma, P. (2020). A nationwide survey of psychological distress among italian people during the COVID-19 pandemic: Immediate psychological responses and associated factors. International Journal of Environmental Research and Public Health, 17(9), 3165.

Nikčević, A. V., \& Spada, M. M. (2020). The COVID-19 anxiety syndrome scale: Development and psychometric properties. Psychiatry research, 292, 113322. https://doi.org/10.1016/j.psychres.2020.113322.

Nikčević, A. V., Marino, C., Kolubinski, D. C., Leach, D., \& Spada, M. M. (2021). Modelling the contribution of the Big Five personality traits, health anxiety, and COVID-19 psychological distress to generalised anxiety and depressive symptoms during the COVID-19 pandemic. Journal of affective disorders, 279, 578-584. https://doi.org/10.1016/j.jad.2020.10.053.

Osofsky, J. D., Osofsky, H. J., Weems, C. F., King, L., \& Hansel, T. C. (2015). Trajectories of posttraumatic stress disorder symptoms among youth exposed to both natural and technological disasters. Journal of Child Psychiatry and Psychology, 56, 1347-1355; https://doi.org/10.1111/jepp.12420.

Pierce, M, Hope, H, Ford, T, Hatch, S, Hotopf, M, John A. (2020). Mental health before and during the COVID-19 pandemic: a longitudinal probability sample survey of the UK population. Lancet Psychiatry, 7: 883-92. doi: 10.1016/S2215-0366(20)30308-4.

Putnam, R. (2000). Bowling alone: the collapse and revival of American community. New York: Simon \& Schuster.

Putnam, R. (2001). Social capital: Measurement and consequences. Canadian Journal of Policy Research, 2(1), 41-51.

Rhodes, J., Chan, C., Paxson, C., Rouse, C. E., Waters, M., \& Fussell, E. (2010). The impact of hurricane Katrina on the mental and physical health of low-income parents in New Orleans.

Shevlin, M., McBride, O., Murphy, J., Miller, J. G., Hartman, T. K., Levita, L., ... \& Bennett, K. M. (2020). Anxiety, Depression, Traumatic Stress, and COVID-19 Related Anxiety in the UK General Population During the COVID-19 Pandemic. PsyArXiv, 18 Apr. 2020. Web.

Smetana, J.G, Campione-Barr, N, Metzger, A. (2006). Adolescent development in interpersonal and societal contexts. Annual Review of Psychology, 2006;57:255-84. doi: 10.1146/annurev.psych.57.102904.190124. PMID: 16318596.

Twenge, J. (2017). I Gen. Why Today's Super-Connected Kids Are Growing Up Less Rebellious, More Tolerant, Less Happy--and Completely Unprepared for Adulthood-and What That Means for the Rest of Us. New York: Atria Books. 
Wilson, B. P. (1999). The Phenomenon of Grade Inflation in Higher Education. National Forum, vol. 79, no. 4, 1999, p. 38. Gale Academic OneFile, . Accessed 1 Feb. 2021.

Zandifar, A., \& Badrfam, R. (2020). Iranian mental health during the COVID-19 epidemic. Asian Journal of Psychiatry, 51, 101990. https://doi.org/10.1016/j.ajp.2020.101990. 